\title{
Estudo piloto para elementos de controle solar desenvolvidos com modelagem paramétrica e fabricação digital
}

\author{
Pilot study for solar shading devices developed with \\ parametric modeling and digital fabrication
}

\section{Rafael Prado Cartana \\ Fernando Oscar Ruttkay Pereira Adir Mayer}

\section{Resumo

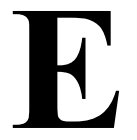

ste estudo piloto tem por objetivo analisar a transmissão de radiação solar, o desempenho lumínico e a capacidade de redução da probabilidade de ofuscamento de elementos de controle solar com formas complexas, desenvolvidos com modelagem paramétrica e fabricação digital. Como método, foi inicialmente utilizada a suíte de aplicativos Rhinoceros3D+Grasshopper para a modelagem paramétrica dos elementos de controle solar. As avaliações de desempenho foram realizadas empregando-se simulações computacionais e medições em protótipos. Para as simulações foram utilizados os plug-ins Diva-for-Rhino e Ladybug. Para as medições foi produzido, através de fabricação digital, um protótipo utilizado para avaliações de ofuscamento através de fotografias HDR. Como principais resultados, observa-se que o emprego dos elementos analisados contribuiu com o controle da admissão de radiação solar, melhorou a distribuição da luz natural e reduziu o ofuscamento nos ambientes de análise, confirmando a confiabilidade dos procedimentos metodológicos empregados. Destacam-se os efeitos da profundidade e inclinação nos elementos analisados respectivamente à distribuição da luz natural e à seletividade na admissão de radiação solar entre inverno e verão. Por fim, os mascaramentos demonstram que, apesar do desenvolvimento de ferramentas de modelagem e simulação, a simples compreensão da geometria da insolação segue imprescindível para o adequado desempenho dos elementos de controle solar.

Palavras-chave: Elementos de controle solar. Modelagem paramétrica. Desempenho lumínico.

\begin{abstract}
This pilot study aims to analyze the solar radiation transmission, the daylight performance and the glare reduction probability of complex shape solar control devices, developed with parametric modeling and digital fabrication. As methodology, initially the Rhinoceros $3 D+$ Grasshopper digital tools suite was used for the parametric modeling of solar control devices. The performance evaluations were performed by computational simulation and measurements in prototypes.

For the simulations, the Diva-for-Rhino and Ladybug plug-ins were used. For the measurements was made, through digital fabrication, a prototype used for glare evaluations through HDR photographs. As main results, the solar control devices contributed to the control of solar radiation admission, better daylight distribution and glare reduction in the indoor analysis environment, confirming the reliability of the methodological procedures employed. Is important to highlight the effects of depth and inclination of the devices analyzed, respectively to the daylight distribution and selectivity in the admission of solar radiation between winter and summer. Finally, the shading masks show that despite all the development of modeling and simulation tools, the simple understanding of the solar geometry is still essential for the adequate performance of the solar control devices.
\end{abstract}

Recebido em 18/11/17 Aceito em 27/02/18

Universidade do Vale do Itajaí Balneário Camboriú - SC - Brasil

Keywords: Solar control devices. Parametric modeling. Daylight performance. 


\section{Introdução}

Considerando a importância do ambiente construído no consumo energético total e tendo em vista que os envelopes construtivos das edificações são responsáveis pelas trocas térmicas com o meio e pela admissão de luz natural, destaca-se que o desempenho dos sistemas de fachadas vem se tornando cada vez mais importante na produção arquitetônica contemporânea, principalmente devido ao aumento das áreas envidraçadas nos edifícios atuais. Observa-se que nesse cenário os elementos de controle solar, quando corretamente empregados, podem contribuir com o conforto e desempenho energético nas edificações (BADER, 2010; FAJKUS, 2013; CHO; YOO; KIM, 2014).

Em um estudo sobre a aplicação de elementos de controle solar em edifícios residenciais, Cho, Yoo e Kim (2014) identificaram relativamente às questões térmicas que de $33 \%$ a $40 \%$ do consumo energético com climatização é decorrente dos ganhos de calor por radiação através das aberturas. Complementarmente, Bader (2010) identificou a possibilidade de redução da radiação incidente na ordem de $75 \%$, considerando configurações de elementos de controle que ainda permitam bom acesso visual aos ambientes externos.

Jakubiec e Reinhart (2011) observaram que os elementos de controle solar podem trazer benefícios ao desempenho lumínico das edificações, contribuindo com uma melhor distribuição da luz natural e redução da probabilidade de desconforto visual. Segundo Reinhart e Wienold (2011), uma avaliação integrada do desempenho lumínico de uma edificação deve considerar a disponibilidade anual da luz natural, o conforto visual e as cargas térmicas.

A partir dessas considerações, este trabalho tem por objetivo analisar a transmissão de radiação solar, o desempenho lumínico e a capacidade de redução da probabilidade de ofuscamento de elementos de controle solar com formas complexas, desenvolvidos com modelagem paramétrica e fabricação digital.

\section{Referencial teórico}

\section{Medidas dinâmicas de desempenho lumínico}

Sendo de ampla utilização para a avaliação da admissão e distribuição da luz natural, as medidas dinâmicas se caracterizam por utilizar condições realísticas da variação de céu e insolação ao longo do tempo, fornecendo resultados para cada hora do ano em cada ponto considerado no ambiente
(NABIL; MARDALJEVIC, 2006). Entre tais medidas, define-se a autonomia da iluminação natural (DA - daylight autonomy) como a porcentagem de horas ocupadas do ano quando um valor mínimo de iluminância, no caso $300 \mathrm{~lx}$, é atingido em determinados pontos no ambiente (REINHART; WIENOLD, 2011). Como a medida DA não apresenta limite superior, dificulta-se a identificação da possibilidade de desconforto por admissão excessiva de luz e, consequentemente, por calor (NABIL; MARDALJEVIC, 2006). Já a medida Useful Daylight Illuminances (UDI) se apresenta mais completa e estabelece limite inferior de $100 \mathrm{~lx}$ e superior de $2.000 \mathrm{~lx}$ para admissão da iluminação natural (REINHART; MARDALJEVIC; ROGERS, 2006). Esses limites de $1001 \mathrm{x}$ e $2.000 \mathrm{~lx}$ podem ser variados de acordo com os critérios mínimos e máximos desejados para admissão de luz natural em determinado ambiente. Tanto as medidas de DA quanto de UDI são expressas em porcentagem das horas do ano (\%) para cada ponto analisado.

\section{Avaliação de desconforto visual por ofuscamento}

Quanto às análises de conforto visual, as medidas Daylight Glare Index (DGI), Unified Glare Rating (UGR) e Daylight Glare Probability (DGP) quantificam de maneira geral o ofuscamento pelo tamanho, posição e luminância da fonte luminosa em comparação com a luminância média do ambiente (JAKUBIEC; REINHART, 2012). Entre as medidas de ofuscamento existentes, a DGP apresenta-se como a mais precisa (WIENOLD; CHRISTOFFERSEN, 2006; JAKUBIEC; REINHART, 2011), se diferenciando das demais por avaliar o valor da iluminância em um plano vertical nos olhos dos observadores. Tais medidas podem ser obtidas tanto por simulação computacional, quanto por medições através do mapeamento das luminâncias utilizando fotografias HDR (high dynamic range), técnica que emprega uma série de fotografias digitais com diferentes exposições para registar a amplitude das luminâncias em uma cena estática (DOYLE; REINHART, 2010).

\section{Ferramentas digitais no processo de projeto e sua materialização}

Paralelamente às questões de conforto e eficiência energética no ambiente construído, observa-se que o emprego de ferramentas digitais nos processos de projeto e produção se estabeleceu nas últimas décadas como um dos principais direcionadores de 
exploração na arquitetura contemporânea (CASTLE, 2013). As tecnologias digitais vêm se tornando importantes não apenas para uma representação gráfica mais ágil e precisa, mas também no auxílio das decisões de projeto, através do emprego integrado de recursos como modelagem paramétrica e simulação computacional (DUNN, 2012), facilitando a concepção, a representação e a avaliação de formas complexas (não ortogonais).

A modelagem paramétrica é um recurso computacional que permite ao projetista definir relações entre elementos ou grupos de elementos, aplicando valores ou expressões para organizar e controlar essas relações (TAGLIARI; FLORIO, 2009). A variabilidade de soluções proporcionada pela modelagem paramétrica facilita que sejam avaliadas diversas alternativas de projeto antes da escolha de uma solução definitiva, situação na qual a simulação computacional pode ser integrada como importante ferramenta de auxílio a tomadas de decisão (KOLAREVIC; MALKAWI, 2005).

Além das mudanças nos processos de projeto, pode-se observar o impacto do desenvolvimento das ferramentas digitais também nos processos de produção na arquitetura contemporânea (OXMAN, 2006). A apropriação e a adaptação de processos de fabricação digital, já empregados na engenharia e design industrial, têm resultado em inovações tecnológicas em uma parte cada vez maior das edificações atuais, o que possibilita maior liberdade formal e customização das soluções de projeto (KOLAREVIC, 2003).

Quanto aos processos de fabricação digital, os objetos podem ser produzidos de diferentes maneiras, de acordo o tipo de maquinário e materiais utilizados. Os métodos de fabricação digital podem ser classificados em quatro categorias: bidimensionais ou por corte, subtrativos, aditivos e formativos (KOLAREVIC, 2003; DUNN, 2012), como apresentado na Figura 1.
Quanto aos métodos de fabricação digital, resumidamente se descreve que nos processos bidimensionais ou por corte materiais em chapas são cortados visando obter uma forma bidimensional, que posteriormente pode ser montada dando a forma volumétrica do projeto. Os métodos subtrativos envolvem a remoção de uma quantidade específica de volume de material a partir de um sólido, utilizando processos elétricos, químicos ou mecânicos. Os métodos de fabricação aditivos envolvem a produção de objetos através da adição de material camada por camada. Entre estes métodos destaca-se a modelagem por fusão e deposição (FDM - fused deposition modeling), utilizada nas impressoras 3D para fabricação de objetos e protótipos em pequena escala. Para produção de objetos em grande escala por métodos aditivos se destacam as técnicas contour crafting e impressão em concreto (concrete printing), que possibilitam a construção de formas complexas em escala real. Por fim, nos métodos de fabricação formativos forças mecânicas, calor ou vapor são aplicados a um material visando à obtenção de um formato desejado através de sua remodelagem ou deformação (KOLAREVIC, 2003; PUPO, 2009; LIM et al., 2012).

\section{Método}

O método aplicado no presente trabalho foi organizado segundo as etapas a seguir:

(a) modelagem paramétrica dos elementos de controle solar;

(b) simulações computacionais referentes à admissão de radiação solar e ao desempenho lumínico;

(c) avaliação de ofuscamento por simulação computacional;

(d) produção de protótipo por fabricação digital e avaliação de ofuscamento utilizando fotografias HDR; e

(e) análises de mascaramentos gerados por simulação computacional.

Figura 1 - Métodos de fabricação digital: (a) bidimensionais ou por corte, (b) subtrativos, (c) aditivos e (d) formativos
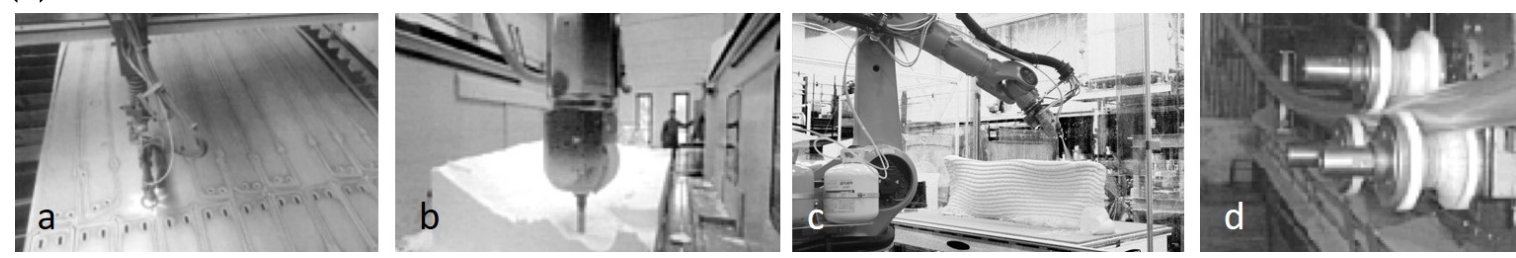

Fonte: Kolarevic (2003). 


\section{Modelagem paramétrica dos elementos de controle solar}

Utilizando a suíte de modelagem paramétrica Rhinoceros3D+Grasshopper, desenvolveu-se um elemento de proteção solar, nomeado neste trabalho como Voronoi-01, devido à utilização de um diagrama de Voronoi para sua geração e distribuição de suas células. Como critérios de escolha dessa geometria, observa-se que os diagramas de Voronoi possibilitam a geração de interessantes resultados compositivos com viabilidade de aplicação como elementos de controle solar, como demonstrado nos exemplos da Figura 2.

Tendo em vista seus resultados estéticos, juntamente a sua facilidade de geração através de ferramentas de modelagem paramétrica, acreditase que veremos cada vez mais a aplicação desse tipo de geometria nas edificações contemporâneas, o que justifica seu estudo. Por fim, essa escolha se baseia também na ideia de explorar a potencialidade da ferramenta de modelagem utilizada, além de investigar o comportamento de formas complexas aplicadas como elementos de controle solar.

Visando ao estabelecimento das relações de causa e efeito entre a geometria e o desempenho dos elementos de controle solar desenvolvidos, foram definidos os seguintes parâmetros geométricos de variação entre os modelos: profundidade, espessura e inclinação dos componentes (no caso, das aletas), como apresentado na Figura 3, juntamente com o algoritmo do Grasshopper e resultado final do modelo Voronoi-01.

Resumidamente, o modelo Voronoi-01 foi gerado através do posicionamento de 123 pontos internamente a um componente Box de $3 \mathrm{~m}$ por 3 $\mathrm{m}$. Os pontos foram definidos manualmente no Rhinoceros3D, visando a uma distribuição aleatória, porém sem que houvesse maior concentração ou espaçamento deles em alguma área específica do modelo. $\mathrm{O}$ algoritmo do Grasshopper (Figura 3) demonstra que, a partir dos pontos, foram geradas as células com o componente Voronoi. As sliders destacadas em vermelho, associadas aos componentes Extrude e Offset, controlam numericamente as variações dos parâmetros geométricos profundidade, espessura e inclinação, o que possibilita diversas configurações geométricas a partir do modelo Base.

A Figura 4 apresenta os quatro modelos de variações paramétricas desenvolvidos. $\mathrm{O}$ modelo (A) Base possui $20 \mathrm{~cm}$ de profundidade e $5 \mathrm{~cm}$ de espessura nas aletas, e não possui inclinação em relação ao plano normal da fachada. A partir do modelo Base foram desenvolvidos os modelos (B) Inclinação $45^{\circ}$, (C) Profundidade $40 \mathrm{~cm} \mathrm{e} \mathrm{(D)}$ Espessura 2,5 cm.

Figura 2 - (a) Airspace Tokyo, Thom Faulders Architecture (b) Alibaba Headquarters, Hassel Architects, (c) Times Eureka Pavilion, NEX Architecture (d) Manuel Gea González Hospital, Arq. Manuel Villagrán, Elegant Embellishments Studio
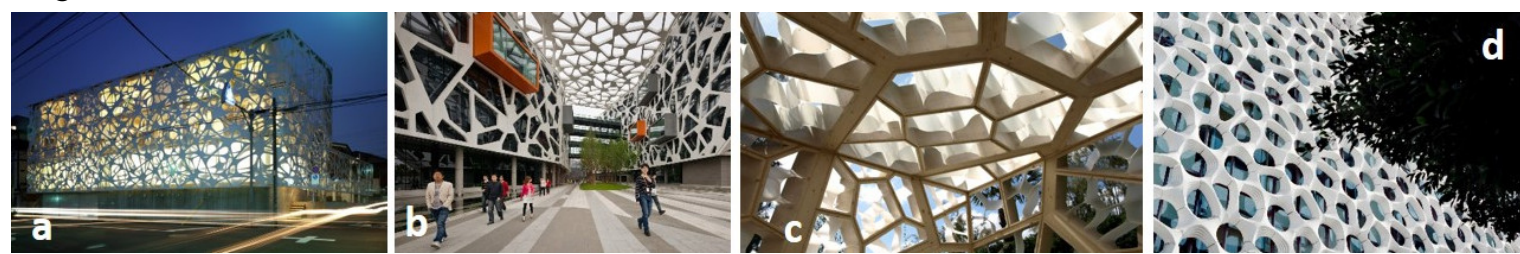

Fontes: (a) Airspace Tokyo (2013); (b) Alibaba Headquarters (2011); (c) Times Eureka Pavilion (2011); e (d) Ellegant Embellishments (2018).

Figura 3 - Parâmetros geométricos dos elementos de controle solar, algoritmo do Grasshopper e visualização do modelo Voronoi-01 

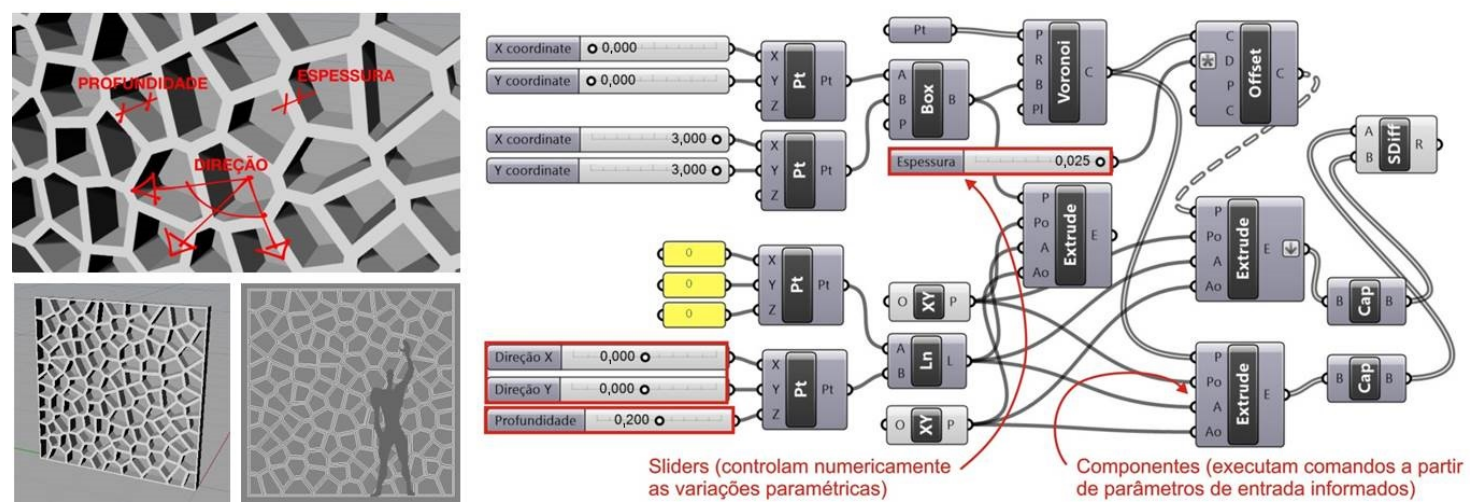

Figura 4 - Variações paramétricas do elemento de controle solar Voronoi-01: modelo (A) Base, (B) Inclinação $45^{\circ}$, (C) Profundidade 40 e (D) Espessura 2,5
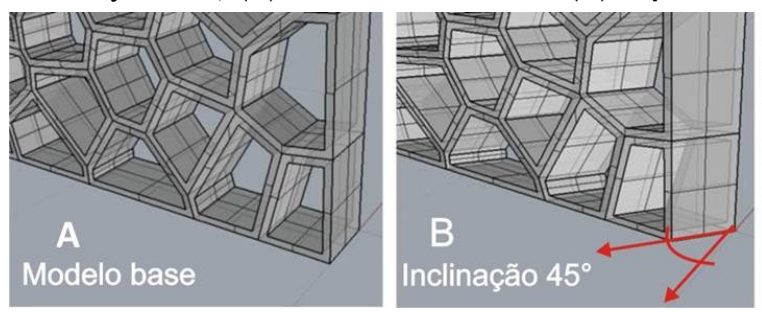

\section{Simulações computacionais referentes à admissão de radiação solar e ao desempenho lumínico}

Utilizando o plug-in DIVA-for-Rhino foram realizadas simulações computacionais relativas à admissão de radiação solar e luz natural. Em todas as simulações, os elementos de controle solar foram posicionados em uma fachada plana, correspondente a um ambiente de $18 \mathrm{~m}^{2}$, com as dimensões demonstradas na Figura 5. A área de fachada $\left(9 \mathrm{~m}^{2}\right)$ foi considerada completamente aberta ao exterior, sem a presença de verga ou peitoril.

O estudo foi realizado para a cidade de Florianópolis, SC (latitude $27^{\circ} \mathrm{S}$ ). Devido a sua maior sensibilidade à admissão de calor por radiação, principalmente durante os períodos de verão, além do desconforto visual causado pela admissão excessiva de iluminação natural em ângulos desfavoráveis à realização de tarefas, foi escolhida a fachada oeste para realização das simulações, nas quais foi utilizado o arquivo climático BRA_Florianopolis.838990_ SWERA.epw, disponível em https://energyplus.net/weather.

Como parâmetros de simulação no DIVA-forRhino, foram definidas as refletâncias das paredes, pisos e teto em $50 \%, 20 \%$ e $70 \%$ respectivamente. Como material dos elementos de controle solar foi utilizado metal cinza-difuso (refletância 50\%). O horário de ocupação do ambiente para as análises de iluminação foi das $8 \mathrm{~h}$ às $18 \mathrm{~h}$.
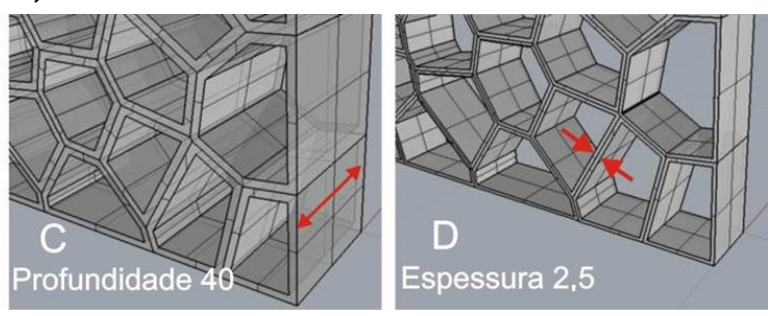

Em relação à radiação solar, foram realizadas simulações para janeiro e julho, escolhidos por corresponderem respectivamente aos meses de maior e menor radiação incidente. Para as análises foi utilizada uma medida comparativa percentual de redução da radiação solar incidente antes e depois da utilização dos elementos de controle solar, denominada neste trabalho como "Coeficiente de admissão da radiação solar incidente (CRS)", expresso em porcentagem. Visando rejeitar qualquer valor diário atípico, foram utilizados valores mensais cumulativos da radiação incidente em Watt-hora por metro quadrado $\left(\mathrm{Wh} / \mathrm{m}^{2}\right)$.

Devido aos condicionantes climáticos de Florianópolis, foi considerada como critério de eficiência nas análises realizadas a capacidade seletiva dos elementos em proporcionar a rejeição da radiação nos períodos de verão e a admissão nos períodos de inverno.

Para as simulações de admissão da luz natural foram empregadas as medidas autonomia da iluminação natural (DA300), useful daylight illuminances (UDI100-2000), e fator de luz diurna médio (FLD) do ambiente. As simulações foram realizadas para o período do ano inteiro, aproveitando a capacidade das medidas dinâmicas em caracterizar o comportamento da luz natural ao longo do tempo.

Para as simulações de radiação foi criado um plano vertical de análise afastado internamente $10 \mathrm{~cm}$ do alinhamento da fachada, com sensores espaçados em 20x20 cm. Para as simulações de admissão da 
luz natural foi criado um plano horizontal de análise a $75 \mathrm{~cm}$ de altura, com sensores espaçados em 50x50 cm (Figura 5).

\section{Avaliação de ofuscamento por simulação computacional}

Nesta etapa foi avaliada a probabilidade de desconforto visual por ofuscamento no ambiente de análise com a aplicação do modelo Base (A) do Voronoi-01. Assim como na etapa anterior, foi utilizado o plug-in DIVA-for-Rhino, que possibilita avaliações dinâmicas (ao longo do ano) ou estáticas (para datas e horários específicos), utilizando a medida DGP (daylight glare probability).

Para as simulações, a visão do observador foi definida a partir de uma câmera afastada internamente $5 \mathrm{~m}$ da fachada e direcionada para a abertura, devido a esse ser normalmente o ângulo de visão mais crítico quanto à probabilidade de ofuscamento.

Comparativamente, foram realizados testes com e sem a presença do elemento de controle solar, realizados de forma dinâmica, avaliando-se o desempenho ao longo do ano e de forma estática, e uma data e horário crítico com entrada direta de sol no ambiente, no caso dia 10 de janeiro às $15 \mathrm{~h}$ (sol no azimute $268^{\circ}$ e altura solar $50^{\circ}$ ). Esse dia foi escolhido por corresponder à data central do mês de janeiro, que se caracteriza por ter a maior admissão cumulativa de radiação solar entre todos os meses do ano na latitude estudada.

\section{Produção de protótipo por fabricação digital e avaliação de ofuscamento com fotografias HDR}

Complementarmente às análises por simulação computacional, nesta etapa foi produzido através de fabricação digital um protótipo em escala 1/20 do modelo Base, posteriormente utilizado para avaliar a probabilidade de desconforto visual por ofuscamento através da técnica de mapeamento das luminâncias por fotografias HDR. O protótipo foi produzido em plástico PLA com uma impressora 3D (FDM - modelagem por fusão e deposição) CubePro (3D Systems), disponível no Laboratório de Conforto Ambiental (Laca) da Univali. Para o ambiente de análise foi produzido em MDF um modelo com as paredes brancas, teto branco e piso na cor original do MDF (Figura 6).

Para a obtenção das fotografias HDR foi utilizada uma câmera Canon EOS 60D (Figura 6), equipada com uma lente Sigma Circular Fisheye $4.5 \mathrm{~mm}$ 1:2.8 DC HSM, disponível no Laboratório de Conforto Ambiental (LabCon) da UFSC. As imagens foram tratadas no aplicativo Photolux 3.2 e forneceram as medidas de daylight glare index (DGI) e unified glare rating (UGR), utilizadas nas análises de ofuscamento.

Visando analisar o conforto visual do ambiente com e sem a presença do elemento de controle solar, foram avaliadas seis situações distintas, separadas em três pares. Na situação do par (1-2) o elemento de controle apenas minimiza a entrada de sol no ambiente; na situação do par (3-4) não há sol incidindo sobre a fachada; e na situação do par (5-6) o elemento de controle impede completamente a entrada de sol no ambiente, como posteriormente apresentado na Figura 14.

O protótipo foi fotografado em um dia de sol e céu claro. Nessas análises não está sendo considerada orientação solar no modelo; as avaliações são feitas apenas em relação à presença ou não de sol (luz direta) no interior do ambiente. Devido às diferenças apesentadas, as escalas dos mapas de luminâncias foram padronizadas de 20 a 40.000 $\mathrm{cd} / \mathrm{m}^{2}$.

Figura 5 - Dimensões dos elementos de controle solar e ambiente de análise. Planos de análise de radiação e iluminação natural
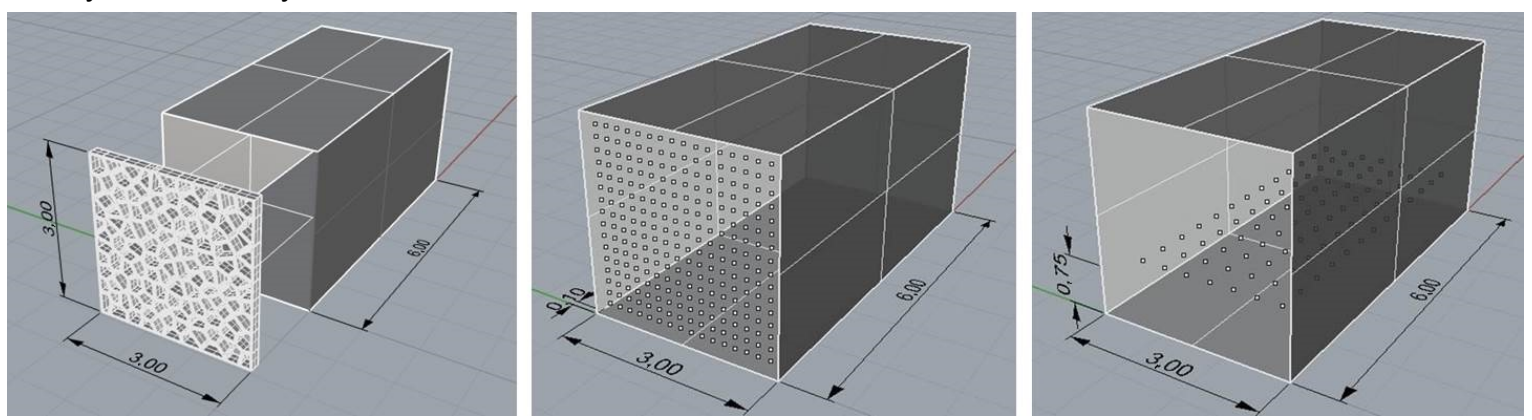

Figura 6 - Impressora 3D CubePro, processo de fabricação, protótipo Voronoi-01(A), ambiente de análise e câmera Canon EOS 60D

72 Cartana, R. P.; Pereira, F. O. R.; Mayer, A. 

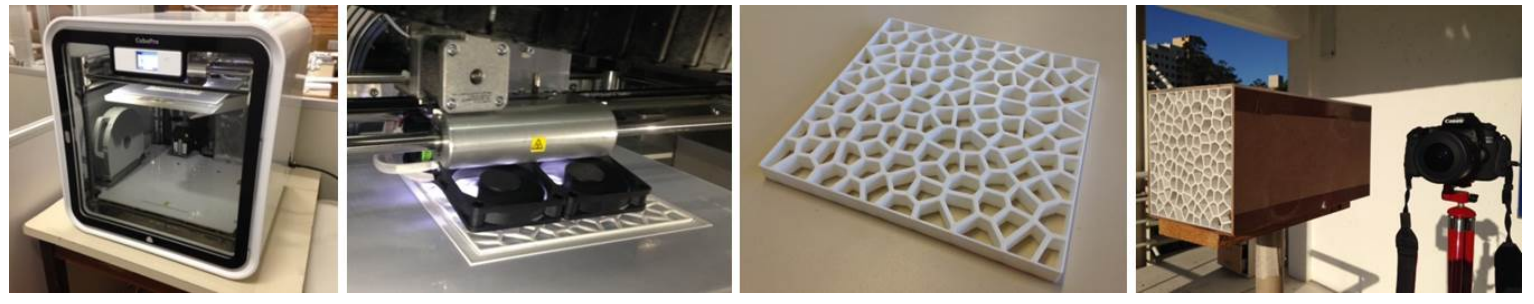

\section{Análises de máscaras de sombra geradas por simulação computacional}

Visando demonstrar as relações entre a geometria da insolação e os resultados de desempenho apresentados nas etapas anteriores, foi utilizado nesta etapa o plug-in Ladybug, que, integrado ao Grasshopper, possibilita a visualização das trajetórias solares ao longo do ano, o mapeamento da radiação solar nas diferentes porções de céu visível e a geração de máscaras de sombra a partir de um ponto específico. Os pontos para geração das máscaras foram alinhados à face inferior e centralizados verticalmente em relação às células dos elementos de controle solar analisados (Figura 7).

A Figura 8 apresenta o algoritmo do Ladybug desenvolvido para geração das máscaras. Esse algoritmo foi organizado em quatro grupos, de acordo com as funções de seus componentes. $\mathrm{Na}$ cor verde, a abertura e importação do arquivo climático utilizado (open weather file e importEPW); na cor violeta, a visualização das trajetórias solares ao longo do ano (sunPath); em amarelo, o mapeamento da radiação solar nas diferentes porções de céu visível (genCumulativeSkyMtx, selectSkyMtx e SkyDome); por fim, em ciano, a geração das máscaras de sombra a partir de pontos específicos (shadingMask). Para a geração das máscaras, o componente shadingMask foi alimentado com as informações testPt, referente ao ponto para geração da máscara, e _context, referente à geometria do elemento de controle solar e ambiente de análise, composto de suas polysurfaces do Rhinoceros.

\section{Resultados e discussões}

Quanto aos resultados das simulações de radiação solar, pode-se observar na Tabela 1 e na Figura 9 o efeito das variações paramétricas para os diferentes modelos e épocas do ano. Como esperado, as menores profundidade e espessura apresentadas no modelo D resultaram nas maiores admissões de radiação do grupo simulado, enquanto as maiores espessuras e profundidades dos modelos A e C resultaram na redução desses valores.

Quanto à seletividade da radiação entre inverno e verão, o modelo B (com inclinação em relação ao plano normal da fachada) foi o único que apresentou essa propriedade. Para quantificar a capacidade seletiva dos elementos, foi dividido o CRS de janeiro pelo de julho. Como resultado, quanto menor o valor obtido, maior é a capacidade do elemento de rejeitar a radiação no verão e admiti-la no inverno.

\section{Figura 7 - Posicionamento do ponto para geração do mascaramento e trajetórias solares geradas no} Ladybug
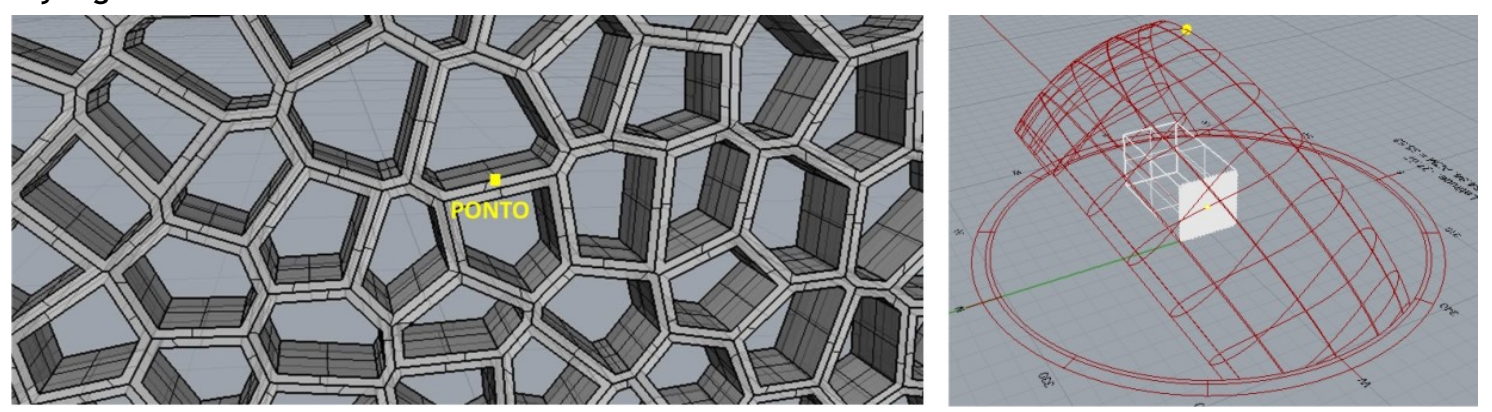
Figura 8 - Algoritmo do Grasshopper (Ladybug) para visualização das trajetórias solares, mapeamento da radiação solar e geração de máscaras de sombra

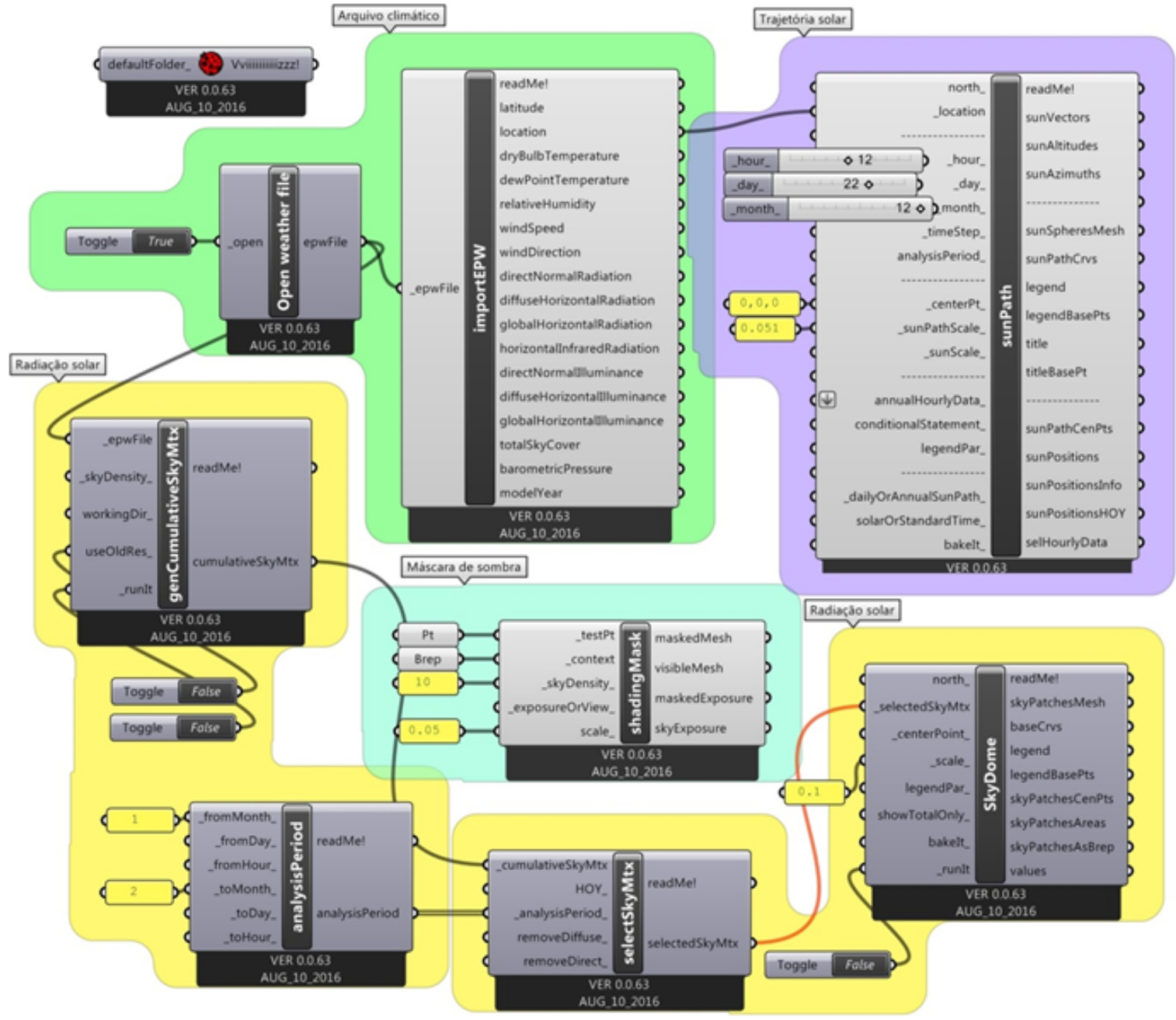

Tabela 1 - Radiação solar incidente, coeficiente de admissão de radiação (CRS) e razão entre janeiro e julho

\begin{tabular}{|c|c|c|c|c|c|}
\hline $\begin{array}{c}\text { Coeficientes/Modelos } \\
\text { avaliados }\end{array}$ & $\begin{array}{c}\text { Sem } \\
\text { obstrução }\end{array}$ & $\begin{array}{c}\text { (A) } \\
\text { Modelo } \\
\text { Base }\end{array}$ & $\begin{array}{c}\text { (B) } \\
\text { Inclinação } \\
45^{\circ}\end{array}$ & $\begin{array}{c}(C) \\
\text { Profundidade } \\
40\end{array}$ & $\begin{array}{c}\text { (D) } \\
\text { Espessura } \\
2,5\end{array}$ \\
\hline $\begin{array}{l}\text { Radiação }\left(\mathrm{Kwh} / \mathrm{m}^{2}\right) \\
\text { Janeiro } \\
\text { Julho }\end{array}$ & $\begin{array}{l}75,48 \\
45,42 \\
\end{array}$ & $\begin{array}{l}25,52 \\
11,06 \\
\end{array}$ & $\begin{array}{l}14,98 \\
15,71\end{array}$ & $\begin{array}{r}14,69 \\
5,82 \\
\end{array}$ & $\begin{array}{l}34,56 \\
16,19 \\
\end{array}$ \\
\hline \multicolumn{6}{|c|}{ Coefic. adm. rad. solar CRS (\%) } \\
\hline $\begin{array}{l}\text { Janeiro } \\
\text { Julho } \\
\text { Razão entre janeiro e julho }\end{array}$ & & $\begin{array}{r}33,81 \\
26,01 \\
1,30\end{array}$ & $\begin{array}{r}19,85 \\
36,95 \\
0,54\end{array}$ & $\begin{array}{r}19,46 \\
13,69 \\
1,42\end{array}$ & $\begin{array}{r}45,79 \\
38,08 \\
1,20\end{array}$ \\
\hline
\end{tabular}

74 Cartana, R. P.; Pereira, F. O. R.; Mayer, A. 
Figura 9 - Comparação dos coeficientes de admissão de radiação para os meses de janeiro e julho

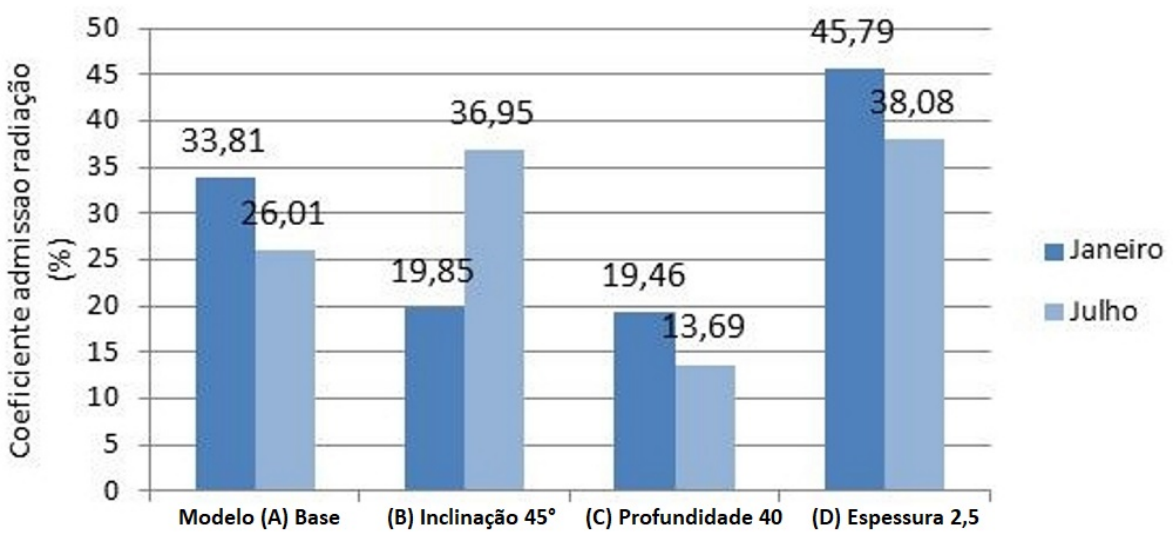

Figura 10 - Análise de insolação para o modelo B, carta solar para latitude $27^{\circ}$ S, relação entre os azimutes de inverno e verão

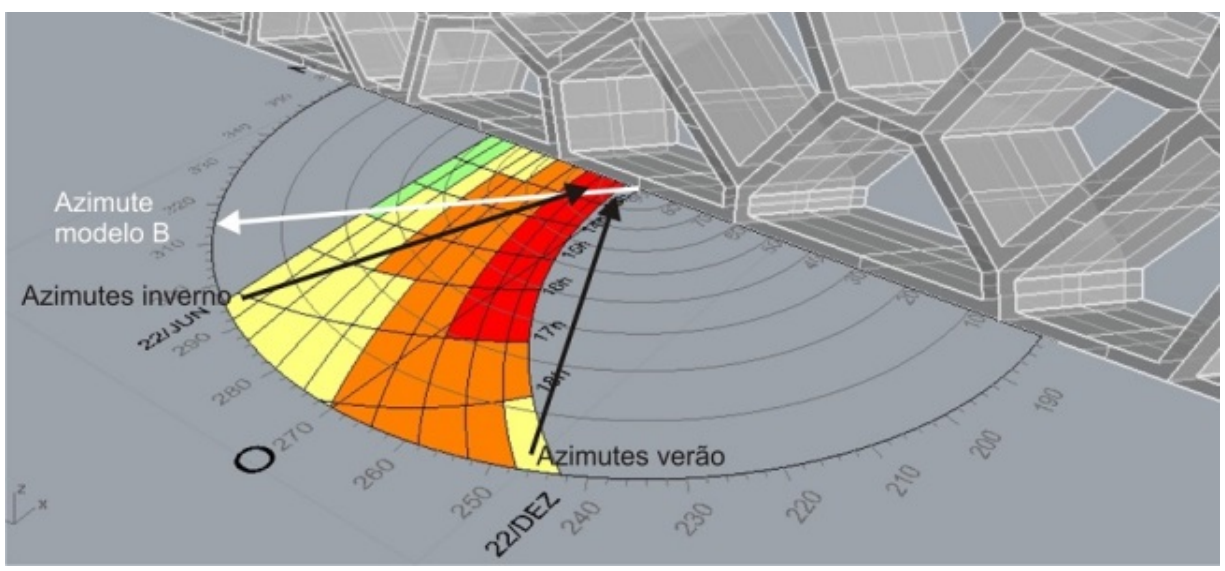

Tabela 2 - Fator de luz diurna médio (FLD), autonomia da iluminação natural média (DA300) e useful daylight illuminances médio (UDI100-2000)

\begin{tabular}{|c|c|c|c|c|c|}
\hline $\begin{array}{c}\text { Coeficientes/Modelos } \\
\text { avaliados }\end{array}$ & $\underset{\text { obstrução }}{\text { Sem }}$ & $\begin{array}{c}\text { (A) } \\
\text { Modelo } \\
\text { Base }\end{array}$ & $\begin{array}{c}\text { (B) } \\
\text { Inclinação } \\
4^{\circ}\end{array}$ & $\begin{array}{c}\text { (C) } \\
\text { Profundidad } \\
\text { e } 40\end{array}$ & $\begin{array}{c}\text { (D) } \\
\text { Espessura } \\
2,5 \\
\end{array}$ \\
\hline $\begin{array}{l}\text { Fator de luz diurna médio } \\
\text { - FLD }(\%)\end{array}$ & 10,00 & 2,10 & 1,50 & 1,00 & 3,10 \\
\hline $\begin{array}{l}\text { Autonomia da luz natural } \\
\text { média - DA }(\%)\end{array}$ & 93,89 & 68,04 & 55,34 & 41,08 & 81,69 \\
\hline $\begin{array}{l}\text { Useful daylight } \\
\text { illuminances médio - UDI } \\
(\%)\end{array}$ & 58,75 & 85,62 & 76,42 & 88,14 & 80,40 \\
\hline $\begin{array}{l}\text { A Figura } 10 \text { demonstra } \\
\text { compreensão da geometri } \\
\text { concepção dos elementos } \\
\text { caso o efeito dos diferentes a } \\
\text { e verão. A inclinação para no } \\
\text { do modelo B favorece a a } \\
\text { durante o inverno e sua rejei } \\
\text { que ajuda no condicion } \\
\text { ambiente em análise. }\end{array}$ & $\begin{array}{l}\text { a importâ1 } \\
\text { da insola } \\
\text { e controle s } \\
\text { zimutes entre } \\
\text { roeste (azim } \\
\text { dmissão de } \\
\text { ão durante o } \\
\text { mento pass }\end{array}$ & $\begin{array}{r}\text { da } \\
\text { na } \\
\text { no } \\
\text { erno } \\
15^{\circ} \text { ) } \\
\text { ação } \\
\text { a,o, o } \\
\text { do }\end{array}$ & \multirow{2}{*}{\multicolumn{3}{|c|}{$\begin{array}{l}\text { sem obstrução apresentou elevados níveis de FLD } \\
\text { e DA médios, indicando excesso de admissão de } \\
\text { luz na região próximo à fachada, o que se } \\
\text { comprova pelo baixo valor médio do UDI } \\
(58,75 \%) \text {, apresentado na Tabela } 2 \text {, e sua } \\
\text { distribuição espacial, apresentada na Figura } 11 \text {. A } \\
\text { linha vermelha apresentada na imagem de UDI do } \\
\text { ambiente desobstruído exemplifica os pontos onde } \\
\text { a admissão de luz foi considerada excessiva, nos } \\
\text { quais os valores de iluminâncias superam os } 2.000 \\
\text { lx por mais de } 75 \% \text { das horas do ano. }\end{array}$}} \\
\hline omo resultado das simulaç & & & & & \\
\hline
\end{tabular}


Em todos os casos avaliados, a presença dos elementos de controle solar proporcionou redução dos valores de DA e distribuição espacial mais homogênea dos valores de UDI, com destaque para o modelo $\mathrm{C}$ (profundidade de $40 \mathrm{~cm}$ ), que apresentou valor médio de UDI em $88,14 \%$, demonstrando a ação dos elementos de controle solar como "prateleiras de luz", o que reduz a admissão excessiva próximo à fachada e conduz a luz para a região mais profunda do ambiente. Cabe também observar na Figura 11 a distribuição da iluminação (DA e UDI) assimétrica no modelo B (inclinado) em função de sua geometria.

Figura 11 - Modelos analisados: autonomia da iluminação natural (DA300) e useful daylight illuminances (UDI100-2000)
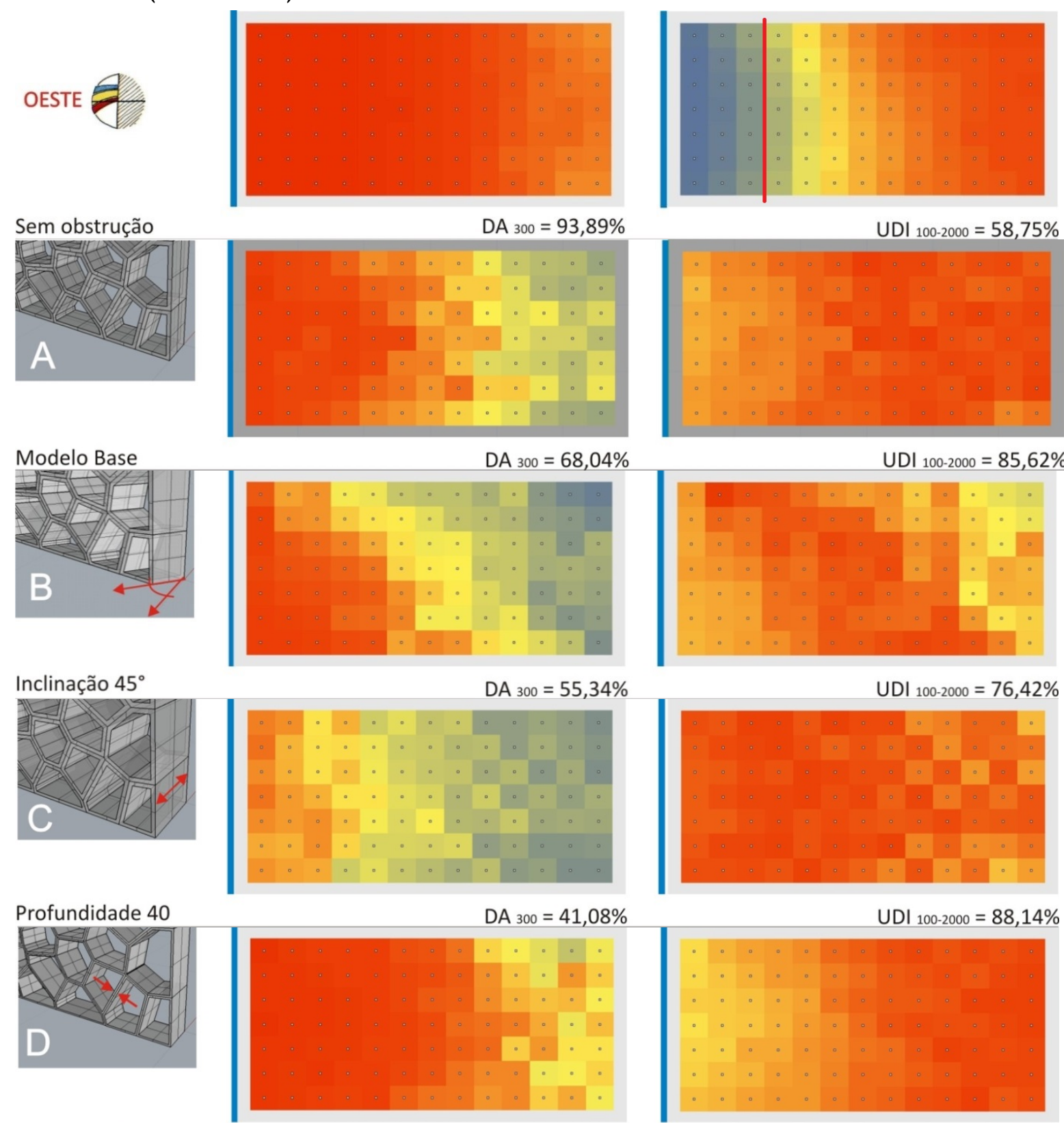

\section{Espessura 2.5} Legenda

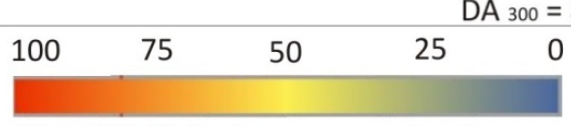

DA e UDI: \% das horas ocupadas do ano
Elemento de controle solar
UDI $100-2000=88,14 \%$

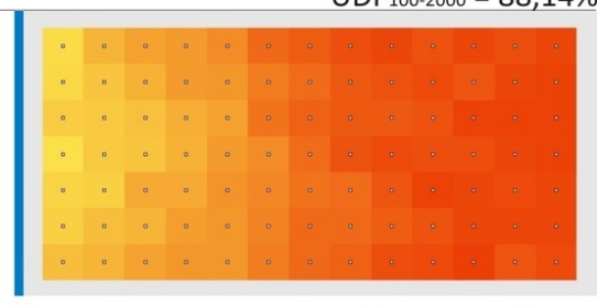

UDI ${ }_{100-2000}=80,4 \%$

OESTE

Orientação 
Observa-se que a utilização das medidas dinâmicas de iluminação natural visou caracterizar o comportamento percentual de cada ponto médio do ambiente de análise em todas as épocas do ano, com horário de ocupação das $8 \mathrm{~h}$ às $18 \mathrm{~h}$, como referido na metodologia. Entretanto, relacionando o desempenho dos elementos de controle solar à geometria da insolação do ambiente de análise com orientação oeste, observa-se nas informações presentes na Tabela 1 (radiação solar incidente) e nos gráficos de distribuição anual da probabilidade de ofuscamento apresentados na Figura 12 que a admissão excessiva de luz e radiação se concentra nos períodos de verão, fundamentalmente nos períodos da tarde, situação na qual os elementos de controle solar se fazem mais necessários.

Quanto às avaliações de conforto visual por simulação, pode-se verificar que o elemento de controle proporcionou redução na probabilidade de ofuscamento tanto para a avaliação dinâmica, ao longo do ano (Figura 12), quanto para a avaliação estática, para data e horário específico (Figura 13).

Para a avaliação dinâmica, o ambiente de análise sem a presença do elemento de controle solar apresentou ofuscamento perturbador ou intolerável $(\mathrm{DGP} \geq 0,4)$ em $25,6 \%$ das horas do ano. Com a presença do elemento de controle solar, esse valor caiu para $8,3 \%$ das horas do ano. O resultado gráfico desses valores pode ser observado nas imagens (a) e (b) da Figura 13. Cabe também observar a coerência na relação entre a geometria da insolação e a análise de DGP anual, na qual as situações críticas ocorrem no verão e nos períodos da tarde, situação em que a luz direta do sol atinge mais intensamente $o$ interior do ambiente.

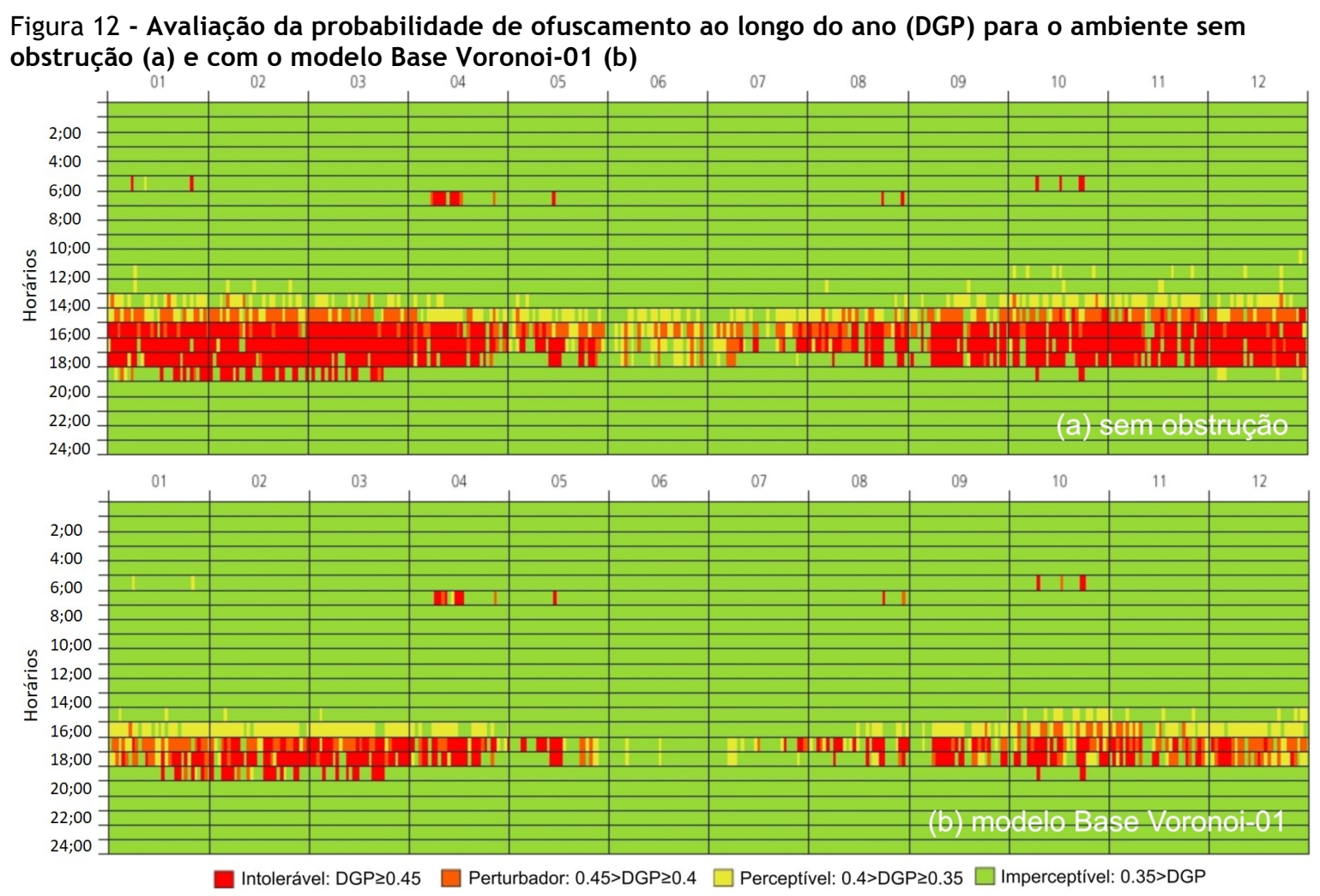

Fonte: Jakubiec e Reinhart (2010).

Nota: Eixo X: meses do ano e Eixo Y: horas do dia. Escala de ofuscamento. 
Figura 13 - Avaliação da probabilidade de ofuscamento (DGP) para o dia 10 de janeiro às $15 \mathrm{~h}$ para o ambiente sem obstrução (a) e com o modelo Base Voronoi-01 (b)

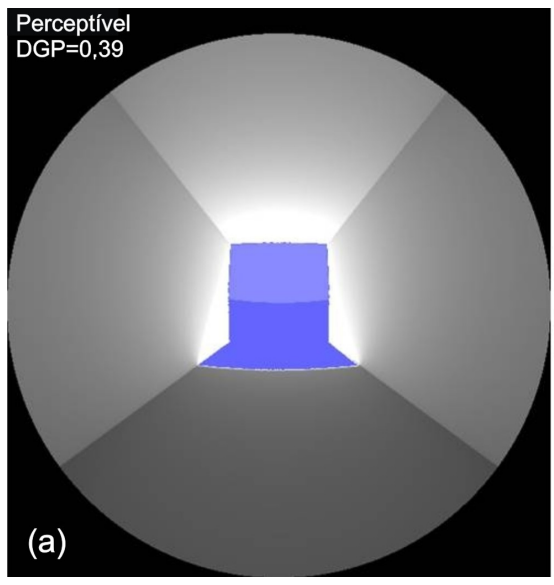

Considerando que o presente trabalho é um estudo piloto, em parte utilizado para o aprimoramento de procedimentos metodológicos para avaliação de elementos de controle solar com formas complexas, observa-se que os resultados da medida DGP confirmam o desempenho estimado entre as duas situações avaliadas (com e sem a presença dos elementos de controle solar) para redução da probabilidade de ofuscamento tanto para a avaliação dinâmica quanto para a avaliação estática. Isso indica confiabilidade na metodologia empregada.

Confirmando os resultados da avaliação dinâmica, na avaliação estática (10 de janeiro às $15 \mathrm{~h}$ ) os valores de DGP variaram de 0,39 (perceptível), sem a presença do elemento de controle, para 0,29 (imperceptível), com a presença do elemento de controle, o que pode ser observado na Figura 13.

A Figura 14 apresenta os resultados das fotografias HDR complementarmente utilizadas para avaliação de ofuscamento para cada uma das seis situações distintas avaliadas, organizadas em pares. Como descrito na metodologia, na situação do par (1-2) o elemento de controle apenas minimiza a entrada de sol no ambiente; na situação do par (3-4) não há sol incidindo sobre a fachada; e na situação do par (5-6) o elemento de controle impede completamente a entrada de sol no ambiente. Sintetizando os resultados obtidos através do tratamento das imagens HDR no aplicativo Photolux, a Tabela 3 apresenta comparativamente as medidas e índices iluminância média (lux), luminâncias $\left(\mathrm{cd} / \mathrm{m}^{2}\right)$, unified glare rating (UGR) e daylight glare index (DGI).

A redução nos valores de iluminâncias e luminâncias médias de acordo com presença dos

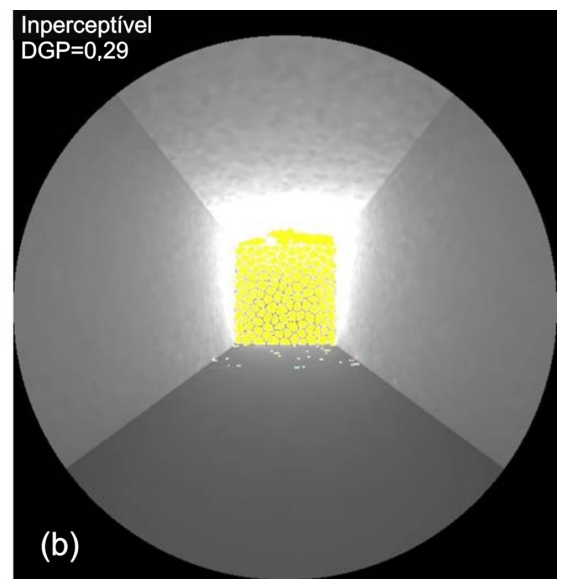

elementos de controle solar indica confiabilidade no emprego de fotografias HDR para representar o fenômeno da admissão e distribuição da luz no ambiente de análise. Assim como nas avaliações de ofuscamento por simulação computacional, observa-se que, além da análise comparativa entre as situações avaliadas (com e sem a presença dos elementos de controle solar), a validade desses experimentos reside também na avaliação dos procedimentos metodológicos, a partir da confirmação dos resultados estimados, como pode ser observado na Tabela 3, na qual os casos (2), (4) e (6) apresentam menores valores de iluminâncias e luminâncias médias que seus pares (1), (3) e (5), que não possuem elementos de controle solar.

Em relação ao conforto visual avaliado pelas medidas UGR e DGI, a presença dos elementos de controle solar coerentemente resultou em redução da probabilidade de ofuscamento nos três pares de casos analisados. Destaca-se a maior redução no caso (5-6), em que o elemento obstrui completamente a entrada direta de sol no ambiente, resultando em uma distribuição mais homogênea da luz natural admitida.

Ainda, quanto às avaliações de ofuscamento através de fotografias HDR, é importante observar que o conforto visual dos ambientes e a distribuição homogênea da luz natural não significam a garantia de iluminação em níveis suficientes ou ideais. Essas informações de desempenho neste trabalho podem ser verificadas principalmente pelos valores de UDI apresentados na Tabela 2 e na Figura 11, nas quais se observa que todos os ambientes de análise com a presença dos elementos de controle solar permanecem com níveis de iluminação entre 100 lx e 2.000 lx acima de $75 \%$ das horas do ano. 


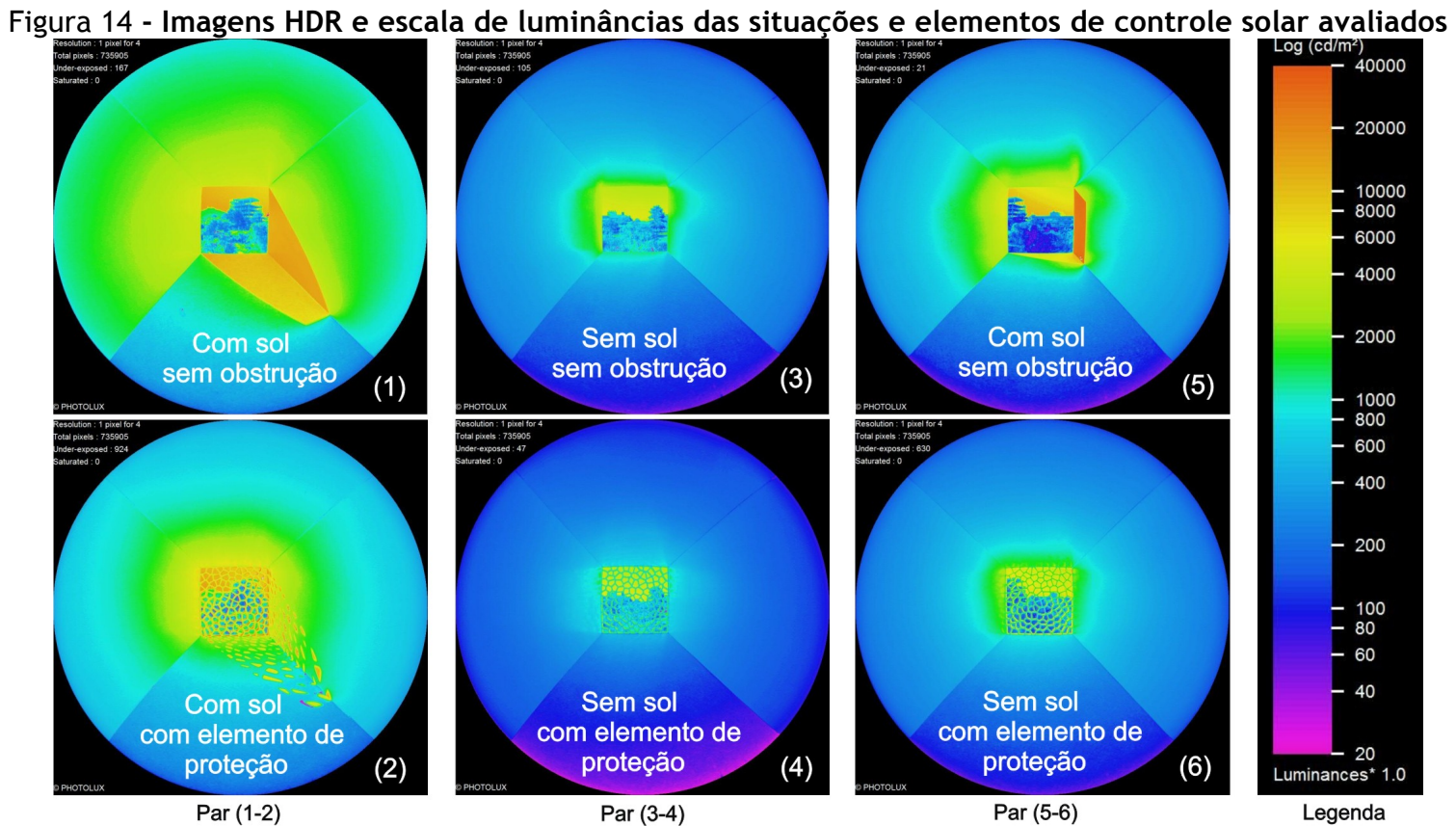

Tabela 3 - Valores obtidos para avaliação de ofuscamento por técnica HDR

\begin{tabular}{|c|c|c|c|c|c|c|}
\hline Situações avaliadas & $\begin{array}{l}\text { Iluminância } \\
\text { Média (lux) }\end{array}$ & $\begin{array}{c}\text { Luminância } \\
\text { Mínima } \\
\left(\mathbf{c d} / \mathbf{m}^{2}\right) \\
\end{array}$ & $\begin{array}{c}\text { Luminância } \\
\text { Máxima } \\
\left(\mathbf{c d} / \mathbf{m}^{2}\right) \\
\end{array}$ & $\begin{array}{c}\text { Luminância } \\
\begin{array}{c}\text { Média } \\
\left(\mathbf{c d} / \mathbf{m}^{2}\right)\end{array} \\
\end{array}$ & UGR & DGI \\
\hline (1) Sem obstrução (com entrada sol) & 10.700 & 110 & 17.000 & 2.230 & 28,9 & 33,6 \\
\hline (2) Voronoi-01 (com entrada sol) & 6.800 & 79 & 79.000 & 1.340 & 28,4 & 33,1 \\
\hline (3) Sem obstrução (sem entrada sol) & 2.260 & 38 & 6.500 & 450 & 24,9 & 30,5 \\
\hline (4) Voronoi-01 (sem entrada sol) & 1.360 & 19 & 6.400 & 266 & 24 & 29,4 \\
\hline (5) Sem obstrução (com entrada sol) & 4.400 & 59 & 17.000 & 870 & 28,5 & 33,2 \\
\hline (6) Voronoi-01 (sem entrada sol) & 2.360 & 37 & 21.100 & 460 & 25 & 29,9 \\
\hline
\end{tabular}

Fonte: Doyle e Reinhart (2010).

Nota: Medidas de iluminação: iluminância média (lux), luminâncias (cd/m²); e mediadas de ofuscamento: UGR e DGI. Escala de cores indicando classificação de desconforto por ofuscamento.

Por fim, estabelecendo uma relação entre o protótipo produzido em escala $1 / 20$ e suas possibilidades de fabricação em escala real, sugere-se que os elementos de controle solar estudados poderiam ser materializados tanto através de métodos bidimensionais, empregandose materiais de maior durabilidade, próprios para uso externo, como chapas metálicas, chapas de madeira processada, fórmicas, placas cimentícias, entre outros, quanto por métodos aditivos como concrete printing ou contour crafting, usando maquinários com maiores dimensões de produção do que a impressora 3D utilizada, como citado no referencial teórico deste trabalho.

Complementarmente a todos os demais resultados, a Figura 15 apresenta as máscaras de sombra para os modelos A, B e C para orientação oeste, geradas com o plug-in Ladybug. Além das máscaras, são apresentados os mapeamentos da radiação solar total (direta, somada à difusa) sobreposta às trajetórias solares para os meses de janeiro e julho, o que facilita a compreensão do comportamento dos elementos de controle solar em função de sua geometria e o consequente acesso a diferentes porções de céu visível.

Como resultados, observa-se comparativamente que os modelos A e B, com $20 \mathrm{~cm}$ de profundidade, apresentam uma área de céu visível semelhante, entretanto o modelo A (perpendicular à fachada oeste) encontra-se mais voltado para os azimutes de verão, admitindo percentualmente mais radiação nessa época do ano (razão janeiro/julho=1,3), enquanto a inclinação do modelo $\mathrm{B}$ favorece a admissão de radiação no inverno (razão janeiro/julho=0,54). 
Figura 15 - Ladybug: trajetórias solares com mapeamento da radiação solar nas diferentes porções de céu e máscaras de sombra para orientação oeste, modelos A, B e C

Voronoi Piloto - Oeste

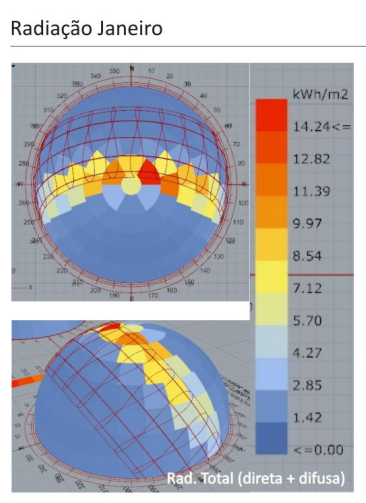

Radiação Julho

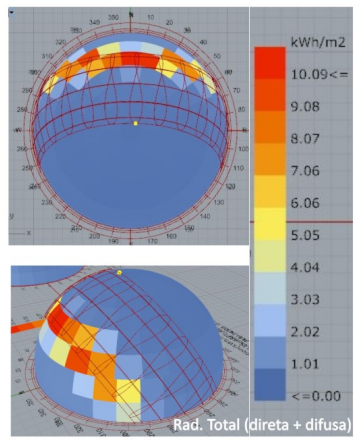

O modelo C, com $40 \mathrm{~cm}$ de profundidade, apresentou mascaramento mais "fechado" que os demais, o que lhe conferiu o menor DA médio $(41,08 \%)$ e FLD médio $(1 \%)$ entre o grupo avaliado; entretanto, como anteriormente referido, o modelo $\mathrm{C}$ apresentou o melhor UDI médio $(88,14 \%)$ entre o grupo avaliado, o que indica a efetividade da profundidade dos elementos de controle solar para uma distribuição mais homogênea da luz natural nos ambientes.

\section{Conclusão}

Este estudo teve como objetivo analisar a transmissão de radiação solar, o desempenho lumínico e a capacidade de redução da probabilidade de ofuscamento de elementos de controle solar com formas complexas, desenvolvidos com modelagem paramétrica e fabricação digital. Como método, foram realizadas avaliações através de simulação computacional e medições em protótipo.

Como principais conclusões deste estudo destacam-se os itens a seguir. Relativamente à admissão seletiva da radiação solar, os resultados demonstram a eficácia na utilização de elementos inclinados visando admitir radiação nos períodos de inverno e rejeitá-la no verão, considerando a orientação solar oeste. Entretanto, cabe observar que os elementos inclinados, apesar de possuírem capacidade seletiva da admissão da radiação, acabaram por distribuir a luz natural de forma assimétrica no ambiente de análise.

Em relação ao ambiente de análise com orientação solar oeste, utilizado nas simulações, quando sem elementos de proteção, apresentou excesso na admissão de radiação solar e distribuição heterogênea da luz natural. Em todos os casos, o emprego dos elementos de controle solar, além de

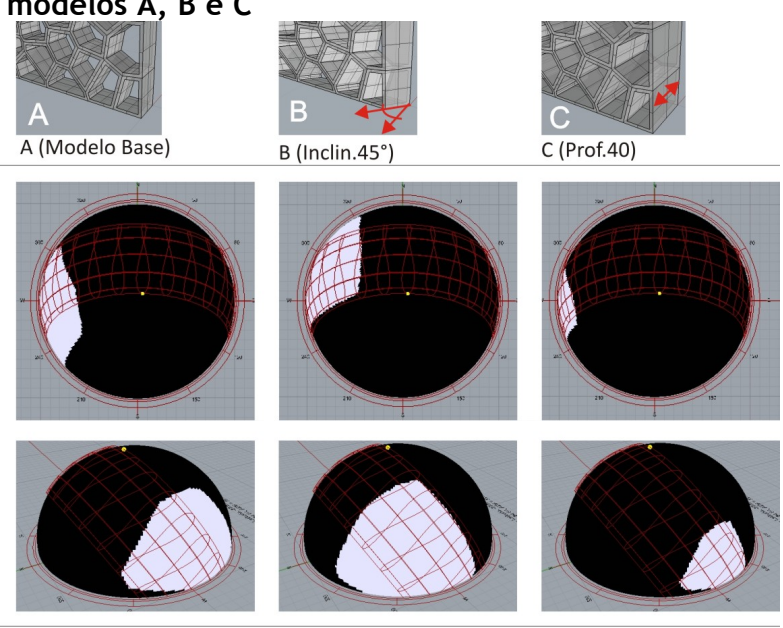

reduzir a radiação admitida, proporcionou melhor distribuição da luz natural, principalmente reduzindo a incidência excessiva na região próximo à fachada, o que pode ser verificado pela distribuição espacial dos valores de UDI, considerando o horário de ocupação das $8 \mathrm{~h}$ às $18 \mathrm{~h}$, utilizado nas simulações.

Em relação às avaliações de conforto visual, os valores de DGP obtidos nas simulações computacionais demonstram, tanto na análise dinâmica quanto na análise estática, que a presença dos elementos de controle solar reduziu a probabilidade de desconforto por ofuscamento. Os resultados das avaliações de ofuscamento utilizando fotografias HDR reforçam os resultados obtidos por simulação, nos quais a presença dos elementos de controle solar, em comparação às aberturas desobstruídas, reduziu a probabilidade de ofuscamento, registrada pelas medidas UGR e DGI empregadas. Confirmando as informações presentes na revisão bibliográfica quanto à precisão das medidas de ofuscamento, a medida DGP apresentou maior sensibilidade em relação às medidas UGR e DGI na caracterização do fenômeno de redução da probabilidade de desconforto visual por ofuscamento.

Por fim, os resultados dos mascaramentos demonstram que, juntamente às tecnologias computacionais de projeto $\mathrm{e}$ às simulações disponíveis para análises de desempenho de elementos de controle solar com formas complexas, a compreensão da geometria da insolação apresenta-se imprescindível para uma admissão seletiva de radiação solar e melhor distribuição da luz natural nos ambientes internos. 


\section{Referências}

AIRSPACE Tokyo. Jul. 2013. Disponível em: $<$ http://faulders-studio.com/AIRSPACETOKYO>. Acesso em: 01 maio 2018.

ALIBABA Headquarters: Hassell. Mar. 2011. Disponível em:

$<$ http://www.archdaily.com/118277/alibabaheadquarters-hassell>. Acesso em: 01 maio 2018.

BADER, S. High-Performance Façades for Commercial Buildings. Austin, Texas: The University of Texas at Austin; School of Architecture, 2010.

CASTLE, H. Editorial - Computation works: the building of algorithmic thought. Architectural Design, v. 83, n. 2, p. 5-5, 2013.

CHO, J.; YOO, C.; KIM, Y. Viability of Exterior Shading Devices For High-Rise Residential Buildings: case study for cooling energy saving and economic feasibility analysis. Energy \& Buildings, v. 82, p. 771-785, 2014.

DOYLE, S.; REINHART, C. High Dynamic Range Imaging \& Glare Analysis: I definitions. 2010. Disponível em:

$<$ http://www.gsd.harvard.edu/research/gsdsquare/P ublications/HDR I Definitions.pdf $>$. Acesso em: 2 nov. 2014.

DUNN, N. Digital Fabrication in Architecture. London: Laurence King, 2012.

\section{ELLEGANT EMBELLISHMENTS. Home.}

Disponível em:

$<$ http://www.elegantembellishments.net/>. Acesso em: 01 maio 2018 .

FAJKUS, M. Superficial Skins? Super Skins?

Shading structures and thermal impact analysis. In: ADVANCED BUILDING SKINS - ENERGY FORUM, Bressanone, 2013. Proceedings... Bressanone, 2013.

JAKUBIEC, A.; REINHART, C. The Use of Glare Metrics in the Design of Daylit Spaces: recommendations for practice. 2010. Disponível em:

$<$ http://www.gsd.harvard.edu/research/gsdsquare/P ublications/2010RadianceWorkshop_GlareIndices. pdf $>$. Acesso em: 2 maio. 2015.

JAKUBIEC, J. A.; REINHART, C. The "Adaptive Zone": a concept for assessing glare throughout daylit spaces. In: BUILDING SIMULATION, Sydney, 2011. Proceedings... Sydney, 2011.

JAKUBIEC, J.; REINHART, C. The "Adaptive Zone": a concept for assessing discomfort glare throughout daylit spaces. Lighting Research and Technology, v. 44, n. 2, p. 149-170, 2012.
KOLAREVIC, B. Architecture in the Digital Age Design and Manufacturing. New York: Spoon, 2003.

KOLAREVIC, B.; MALKAWI, A. Performative Architecture Beyond Instrumentality. New York: Spoon, 2005.

LIM, S. et al. Developments in Construction-Scale Additive Manufacturing Processes. Automation in Construction, v. 21, n. 1, p. 262-268, 2012.

NABIL, A.; MARDALJEVIC, J. Useful Daylight Illuminances: a replacement for daylight factors. Energy and Buildings, v. 38, n. 7, p. 905-913, 2006.

OXMAN, R. Theory and Design in the First Digital Age. Design Studies, v. 27, p. 229-265, 2006.

\section{PUPO, R. T. Inserção da Prototipagem e} Fabricação Digitais no Processo de Projeto: um novo desafio para o ensino de arquitetura. Campinas, 2009. Tese (Doutorado em Engenharia Civil) - Faculdade de Engenharia Civil, Arquitetura e Urbanismo, Universidade Estadual de Campinas, Campinas, 2009.

REINHART, C. F.; WIENOLD, J. The Daylighting Dashboard: a simulation-based design analysis for daylit spaces. Building and Environment, v. 46, n. 2, p. 386-396, 2011.

REINHART, F, C.; MARDALJEVIC, J.; ROGERS, Z. Dynamic Daylight Performance Metrics for Sustainable Building Design. Leukos, v. 3, n. 1, p. 7-31, 2006.

TAGLIARI, A.; FLORIO, W. Fabricação Digital de Superfícies: aplicações da modelagem paramétrica na criação de ornamentos na arquitetura contemporânea. In: CONGRESSO IBEROAMERICANO DE GRÁFICA DIGITAL, 13., São Paulo, 2009. Anais... São Paulo, 2009.

TIMES Eureka Pavilion: Nex Architecture. Jun. 2011. Disponível em:

$<$ http://www.archdaily.com/142509/times-eurekapavilion-nex-architecture $>$. Acesso em $>01$ maio 2018.

WIENOLD, J.; CHRISTOFFERSEN, J.

Evaluation Methods and Development of a New

Glare Prediction Model For Daylight

Environments With the Use of CCD Cameras.

Energy and Buildings, v. 38, n. 7, p. 743-757, 2006.

\section{Agradecimentos}

Os autores agradecem à Fundação de Amparo à Pesquisa e Inovação do Estado de Santa Catarina (Fapesc), pelos recursos financeiros aplicados no 
desenvolvimento e na divulgação deste trabalho, à Universidade Federal de Santa Catarina (UFSC) e à Universidade do Vale do Itajaí (Univali), pelos materiais e equipamentos disponibilizados.

\section{Errata}

No artigo "Estudo piloto para elementos de controle solar desenvolvidos com modelagem paramétrica e fabricação digital", com número de DOI: <http://dx.doi.org/10.1590/s1678-86212018000300268>, publicado no periódico Ambiente Construído, 18(3):67-82.

Na página 67:

Onde se lia no título e no final da página:

"Etudo piloto para elementos de controle solar desenvolvidos com modelagem paramétrica e fabricação digital"

Leia-se:

"Estudo piloto para elementos de controle solar desenvolvidos com modelagem paramétrica e fabricação digital"

Nas páginas ímpares:

Onde se lia:

"Etudo piloto para elementos de controle solar desenvolvidos com modelagem paramétrica e fabricação digital"

Leia-se:

"Estudo piloto para elementos de controle solar desenvolvidos com modelagem paramétrica e fabricação digital"

\section{Rafael Prado Cartana}

Curso de Arquitetura e Urbanismo | Universidade do Vale do Itajaí | Rua $5^{\text {a }}$ Avenida, 1100, Municípios, Campus Balneário Camboriú | Balneário Camboriú - SC - Brasil | CEP 88330-000 | Tel.: (47) 3261-1219 | E-mail: rafaelcartana@gmail.com

\section{Fernando Oscar Ruttkay Pereira}

Programa de Pós-Graduação em Engenharia Civil e Arquitetura, Centro Tecnológico | Universidade Federal de Santa Catarina | Trindade CEP 88040-900 | Caixa Postal 476 | Florianópolis - SC - Brasil | Tel.: (48) 3721-7080 | E-mail: ruttkay.pereira@ufsc.br

\section{Adir Mayer}

Curso de Arquitetura e Urbanismo | Universidade do Vale do Itajaí | E-mail: adirmayer@hotmail.com

\section{Revista Ambiente Construído}

Associação Nacional de Tecnologia do Ambiente Construído

Av. Osvaldo Aranha, $99-3^{\circ}$ andar, Centro

Porto Alegre - RS - Brasil

CEP $90035-190$

Telefone: +55 (51) 3308-4084

Fax: +55 (51) 3308-4054

www.seer.ufrgs.br/ambienteconstruido

E-mail: ambienteconstruido@ufrgs.br 